\title{
Resposta fisiológica de clone de café Conilon sensível à deficiência hídrica enxertado em porta-enxerto tolerante
}

\author{
Vânia Aparecida Silva ${ }^{(1)}$, Werner Camargos Antunes(2), Breno Lourenzzo Salgado Guimarães ${ }^{(2)}$, \\ Rita Márcia Cardoso Paiva ${ }^{(2)}$, Vanisse de Fátima Silva( ${ }^{(3)}$, Maria Amélia Gava Ferrão ${ }^{(4)}$, \\ Fábio Murilo DaMatta ${ }^{(2)}$ e Marcelo Ehlers Loureiro(2)
}

\begin{abstract}
(1)Empresa de Pesquisa Agropecuária de Minas Gerais, Unidade Regional Epamig Sul de Minas, Caixa Postal 176, CEP $37200-000$ Lavras, MG. E-mail: vania.silva@epamig.br (2)Universidade Federal de Viçosa, Departamento de Biologia Vegetal, Av. PH Rolfs, s/no, CEP 36570-000 Viçosa, MG. E-mail: wcantunes@yahoo.com, lourenzzobreno@hotmail.com, ritamarciabqi@hotmail.com, fdamatta@ufv.br mehlers@ufv.br (3)Universidade Federal de Lavras, Departamento de Agricultura, Caixa Postal 3037, CEP $37200-000$ Lavras, MG. E-mail: vanissesilva@yahoo.com ${ }^{(4)}$ Instituto Capixaba de Pesquisa, Assistência Técnica e Extensão Rural, BR 102, Km 94, CEP 29375-000 Venda Nova do Imigrante, ES. E-mail: mferrao@incaper.es.gov.br
\end{abstract}

Resumo - O objetivo deste trabalho foi determinar alterações fisiológicas e de tolerância à seca em clones de café Conilon (Coffea canephora) contrastantes quanto à sensibilidade ao deficit hídrico. Foram avaliadas as enxertias recíprocas entre os clones 109A, sensível ao deficit hídrico, e 120, tolerante - 120/109A, 120/120, 109A/120, 109A/109A -, além de seus respectivos pés-francos. As plantas foram cultivadas em vasos de $12 \mathrm{~L}$ em casa de vegetação. Após seis meses, metade das plantas foi submetida ao deficit hídrico por meio da suspensão da irrigação, até que as folhas atingissem o potencial hídrico de antemanhã de -3,0 MPa. Quando o clone 120 foi usado como porta-enxerto, as plantas apresentaram sistema radicular mais profundo, mas com menor massa, retardaram por mais tempo a desidratação celular das folhas e apresentaram maior eficiência no uso da água. Sob seca severa, os teores de amido e sacarose decresceram em todos os tratamentos, enquanto os teores de glicose, frutose, aminoácidos totais e prolina aumentaram, particularmente nos tratamentos 109A pé-franco, 109A/109A e 120/109A. Essas plantas apresentaram menor eficiência no uso da água. O acúmulo de solutos não foi associado à tolerância à seca. $\mathrm{O}$ uso de porta-enxertos tolerantes à seca contribui para a maior tolerância das plantas ao deficit hídrico.

Termos para indexação: Coffea canephora, deficit hídrico, eficiência no uso da água, enxertia, prolina, tolerância à seca.

\section{Physiological response of Conilon coffee clone sensitive to drought grafted onto tolerant rootstock}

\begin{abstract}
The objective of this work was to determine alterations in physiology and those due to drought tolerance on Conilon coffee (Coffea canephora) contrasting clones regarding the sensitivity to hydric stress. The reciprocal grafting between clones 109A, drought sensitive, and 120, drought tolerant, - 120/109A, $120 / 120,109 \mathrm{~A} / 120,109 \mathrm{~A} / 109 \mathrm{~A}$ - along with their ungrafted control plants (109A and 120) were evaluated. Plants were cultivated in 12-L vases in greenhouse. Six months after grafting, half of the plants was subjected to water deficit, by suspending irrigation until leaves reached the hydric potential of $-3,0 \mathrm{MPa}$. When clone 120 was used as rootstock, plants presented deeper roots, although with lower root-biomass, higher ability to postpone leaf dehydration and higher instantaneous water-use efficiency (WUE). Under severe drought, starch and sucrose contents decreased similarly, regardless of the treatment, whereas leaf concentrations of glucose, fructose, total amino acids and proline were higher in non-grafted 109A, 109A/109A, and 120/109A plants. These plants showed the lowest WUE values. Solute accumulation was not primarily related to drought tolerance. The use of drought tolerant rootstocks improves to drought tolerance in coffee.
\end{abstract}

Index terms: Coffea canephora, water deficit, water-use efficiency, grafting, proline, drought tolerance.

\section{Introdução}

No Brasil, o cultivo do café Conilon tem-se expandido para áreas onde a deficiência hídrica é o principal fator limitante à produção. Para melhorar o rendimento de cafeeiros em ambientes com restrição hídrica, melhoristas têm procurado selecionar genótipos que produzam bem nesses ambientes.

Estudos conduzidos no Espírito Santo têm mostrado grande diversidade genética entre clones de Conilon,

Pesq. agropec. bras., Brasília, v.45, n.5, p.457-464, maio 2010 
quanto à produção sob condições de seca. Nessas condições, observam-se clones sensíveis à seca, com baixo vigor, desfolha considerável e grande comprometimento da produção e clones que exibem bom vigor e produtividades médias praticamente inalteradas. Com o objetivo de identificar e compreender os mecanismos fisiológicos de tolerância ao deficit hídrico em café, DaMatta et al. (2003) selecionaram clones com tolerâncias contrastantes ao deficit hídrico, entre eles, o clone 120, tolerante, e o clone 109A, sensível .

Os principais mecanismos fisiológicos de tolerância diferencial à seca entre clones de Conilon são governados pela eficiência de extração da água do solo e pelas taxas de uso da água pelas plantas (DaMatta et al., 2003; Pinheiro et al., 2005; DaMatta \& Ramalho, 2006). Avaliações fisiológicas sugerem que clones com produção relativamente elevada em condições de seca são capazes de manter potenciais hídricos foliares adequados, por meio da combinação do aprofundamento do sistema radicular e aumento no controle estomático. Além disso, algumas características bioquímicas também são importantes para o aumento da tolerância ao estresse hídrico, entre elas, a manutenção da capacidade de transporte de fotoassimilados da parte aérea para as raízes, que pode permitir maior crescimento radicular e, dessa forma, maior acesso a horizontes mais profundos do solo, de modo a aumentar a absorção de água. Por sua vez, clones sensíveis ao deficit hídrico possuem um controle deficiente da transpiração, com os estômatos respondendo de forma limitada à redução da disponibilidade de água do solo, e também possuem uma baixa capacidade de absorção de água, pois têm sistemas radiculares mais superficiais (Ronchi \& DaMatta, 2007).

Ainfluência do sistema radicular no desenvolvimento das plantas e na tolerância a estresses ambientais tem se tornado bastante evidente com o uso da técnica de enxertias recíprocas (Hartmann et al., 2002). Em frutíferas, como macieira (Policarpo et al., 2000) e videira (Lacono et al., 1998), alguns genótipos de porta-enxertos são capazes de aumentar a tolerância ao deficit hídrico do genótipo enxertado (Atkinson et al., 2000).

Em relação ao café Conilon, não há trabalhos que evidenciem o efeito de porta-enxertos sobre a tolerância à seca de enxertos sensíveis. Tem sido observado apenas que há efeitos positivos de porta-enxertos de Coffea canephora sobre o crescimento e desenvolvimento de enxertos de C. arabica (Fahl et al., 2001; Tomaz et al., 2006).

Os efeitos de porta-enxertos sobre enxertos podem ocorrer por meio de mudanças nos mecanismos fisiológicos da planta, como balanço hormonal, absorção de água, trocas gasosas, translocação de assimilados, entre outros (Sorce et al., 2002; Atkinson et al., 2003).

A perspectiva de utilização de porta-enxertos de clones tolerantes, no aumento da tolerância à seca de genótipos mais sensíveis, pode ampliar o conhecimento sobre as interações fisiológicas verificadas na enxertia entre genótipos com tolerâncias contrastantes ao deficit hídrico.

O objetivo deste trabalho foi determinar alterações fisiológicas e de tolerância à seca em clones de café Conilon contrastantes quanto à sensibilidade ao deficit hídrico.

\section{Material e Métodos}

As plantas de Coffea canephora Pierre var. Conilon foram obtidas no Instituto Capixaba de Pesquisa, Assistência Técnica e Extensão Rural (Incaper). O clone tolerante ao deficit hídrico (120) e o clone sensível (109A) foram utilizados como enxertos e como porta-enxertos, em enxertias recíprocas. Dessa forma, foram avaliadas as autoenxertias 109A/109A e 120/120 e as enxertias recíprocas 120/109A, 109A/120, além dos pés-francos de cada clone.

O experimento foi realizado na Universidade Federal de Viçosa, em Viçosa, Minas Gerais. As enxertias recíprocas entre os clones 109A e 120 foram realizadas pelo método de garfagem em fenda cheia. No momento da enxertia, as mudas estavam com dois pares de folhas, por se tratarem de mudas clonais. Após a enxertia, as mudas foram mantidas em câmara de nebulização fechada por 30 dias.

Após esse período, as mudas enxertadas foram colocadas em casa de vegetação, onde permaneceram por 20 dias, para aclimatação. Uma vez aclimatadas, foram transferidas para vasos de 12 litros. O substrato utilizado para enchimento dos vasos consistiu de uma mistura de solo, areia e esterco bovino $(3: 1: 1, \mathrm{v} / \mathrm{v} / \mathrm{v})$. A adubação foi feita de acordo com a análise do solo, segundo recomendações de Guimarães et al. (1999). As mudas foram mantidas em casa de vegetação, com livre troca de ar. A densidade média de fluxo de 
fótons de radiação fotossinteticamente ativa na casa de vegetação foi de $900 \mu \mathrm{mol} \mathrm{m}^{-2} \mathrm{~s}^{-1}$, ao meio-dia. Os pés-francos foram submetidos às mesmas condições que as enxertias.

O delineamento experimental utilizado foi o de blocos ao acaso, com 12 tratamentos e 5 repetições, em esquema fatorial $6 \times 2$, constituído por quatro enxertias recíprocas entre os clones citados mais os respectivos pés-francos, e dois regimes hídricos. A parcela foi constituída de uma planta por vaso. No momento em que as plantas atingiram seis meses, foram aplicados os tratamentos hídricos, que consistiram da imposição ou não de deficiência hídrica, por meio da suspensão total da rega até que as plantas atingissem o potencial de antemanhã de -3,0 MPa. Foram realizadas análises de potencial hídrico, trocas gasosas, e conteúdo de carboidratos, aminoácidos e prolina em folhas completamente expandidas do terceiro ou quarto par de folhas, a partir do ápice dos ramos plagiotrópicos medianos das plantas.

O potencial hídrico, medido em folhas individuais, no total de cinco folhas por tratamento, com uma bomba de pressão tipo Scholander (Scholander et al., 1965), foi acompanhado de quatro em quatro dias, até que as plantas atingissem o potencial hídrico na antemanhã $\left(\Psi_{\mathrm{am}}\right)$ de -3,0 MPa.

Ao final do experimento, com o objetivo de verificar a ocorrência de possíveis sintomas de incompatibilidade nas enxertias, foram realizadas análises de parâmetros biométricos nas plantas irrigadas. O diâmetro do caule, localizado entre os dois primeiros entrenós, foi mensurado com um paquímetro, e o comprimento do caule e o da maior raiz, com uma fita métrica. A área foliar foi determinada de acordo com o método de dimensões foliares (Barros et al., 1973). As plantas irrigadas foram colhidas e separadas em parte aérea e raiz. Em seguida, a massa de matéria seca dos tecidos, obtida após secagem a $70^{\circ} \mathrm{C}$ em estufa com ventilação forçada, por 72 horas, e o comprimento da maior raiz foram analisados

Quando $\Psi_{\text {am }}$ nas plantas submetidas ao deficit hídrico atingiu $-3,0 \mathrm{MPa}$, foram medidas as taxas de assimilação líquida de carbono (A), a taxa transpiratória (E), a condutância estomática $\left(\mathrm{g}_{\mathrm{s}}\right)$ e a razão entre concentrações interna e externa de $\mathrm{CO}_{2} \quad\left(\mathrm{C}_{\mathrm{i}} / \mathrm{C}_{\mathrm{a}}\right)$. As medições foram feitas em sistema aberto, entre 8 e $9 \mathrm{~h}$, sob luz saturante artificial $\left(1.000 \mu \mathrm{mol} \mathrm{m}^{-2} \mathrm{~s}^{-1}\right)$ e concentração de $\mathrm{CO}_{2}$ ambiente, com um analisador de gás a infravermelho portátil, LCA4, (Analytical Development Company-ADC, Kings Liyn, Reino Unido), conforme descrito por DaMatta et al. (2002). A eficiência do uso da água foi calculada por meio da razão A/E. Durante as medições das trocas gasosas, realizadas em uma folha por planta, no total de cinco folhas por tratamento, a temperatura foliar média foi $22 \pm 2^{\circ} \mathrm{C}$ e a umidade relativa do ar média foi $80 \%$.

No dia em que as plantas atingiram $\Psi_{\text {am }}$ entre $-1,5 \mathrm{e}$ -3,0 MPa, valores correspondentes a deficits hídricos moderado e severo, respectivamente, coletaram-se amostras de folhas para avaliar os efeitos do deficit hídrico na concentração de carboidratos, aminoácidos e prolina. As amostras foliares foram coletadas por volta de $9 \mathrm{~h}$ e imediatamente congeladas em nitrogênio líquido. Subsequentemente, os tecidos foliares foram macerados e, então, submetidos à extração etanólica, determinando-se, na fração solúvel em etanol, os teores de açúcares, aminoácidos e prolina e, na fração insolúvel, os teores de amido (Praxedes et al., 2006).

A análise de variância dos dados a $5 \%$ de probabilidade, pelo teste $\mathrm{F}$, foi realizada, utilizando-se o programa computacional Sisvar (Ferreira, 2008). Quando diferenças significativas foram detectadas, as médias foram comparadas pelo teste de Newman-Keuls, a $5 \%$ de probabilidade.

\section{Resultados e Discussão}

Nas plantas irrigadas, o $\Psi_{\text {am }}$ foi sempre superior a $-0,05 \mathrm{MPa}$. No pé-franco do clone 109A, sensível à seca, e na autoenxertia 109A/109A, o $\Psi_{\text {am }}$ de -3,0 MPa foi alcançado aos 18 dias após a suspensão da irrigação, enquanto no pé-franco do clone 120 , tolerante à seca, e na autoenxertia 120/120, ele foi atingido apenas aos 25 e 27 dias, respectivamente, após a imposição do deficit hídrico (Tabela 1).

O resultado da utilização da enxertia recíproca entre os dois genótipos contrastantes quanto à tolerância à seca sugere uma contribuição do sistema radicular do clone 120 em retardar o deficit hídrico na parte aérea do clone 109A, na medida em que, na enxertia $109 \mathrm{~A} / 120$, o $\Psi_{\text {am }}$ tendeu a diminuir mais lentamente do que nas plantas sensíveis, isto é, o $\Psi_{\text {am }}$ de -3,0 MPa foi alcançado aos 25 dias após a suspensão da irrigação. $\mathrm{Na}$ enxertia 120/109A, o tempo necessário para que isso ocorresse (22 dias) foi maior do que nas plantas sensíveis (18 dias), evidenciando que a parte aérea do 
clone 120 também contribui para maior tolerância à seca. Estes resultados não podem ser explicados por diferenças na área foliar nem pela razão entre massa de matéria seca de raiz e área foliar, que não diferiram significativamente entre os pés-francos dos clones 109A e 120, nem entre as autoenxertias e enxertias recíprocas.

$\mathrm{Na}$ análise dos parâmetros biométricos, não foram verificados sintomas de incompatibilidade entre os clones, pois as características morfológicas, tais como comprimento e diâmetro do caule e as razões entre massa de matéria seca radicular e área foliar e entre a massa de matéria seca radicular e massa de matéria seca da parte aérea, não diferiram entre os tratamentos 109A/120 e 120/109A (Tabela 2). Entretanto, o processo de enxertia reduziu a massa de matéria seca total do sistema radicular e a biomassa total da planta, especialmente em relação aos resultados do pé-franco 109A. Observou-se também efeito das enxertias na redução da área foliar.

As diferenças mais interessantes observadas nos parâmetros biométricos estão relacionadas ao sistema radicular. Apesar de a biomassa radicular ter sido $20 \%$ maior no pé-franco 109A do que no pé-franco

Tabela 1. Número de dias para que os pés-francos dos clones 109A e 120 de Coffea canephora e suas enxertias recíprocas alcançassem potencial hídrico de antemanhã de $-3,0 \mathrm{MPa}$, após a interrupção da irrigação ${ }^{(1)}$.

\begin{tabular}{lc}
\hline Tratamento & Número de dias \\
\hline $109 \mathrm{~A}$ & $18 \pm 1,0 \mathrm{c}$ \\
120 & $25 \pm 1,0 \mathrm{a}$ \\
$109 \mathrm{~A} / 109 \mathrm{~A}$ & $18 \pm 1,0 \mathrm{c}$ \\
$120 / 120$ & $27 \pm 2,0 \mathrm{a}$ \\
$109 \mathrm{~A} / 120$ & $25 \pm 1,0 \mathrm{a}$ \\
$120 / 109 \mathrm{~A}$ & $22 \pm 2,0 \mathrm{~b}$ \\
\hline
\end{tabular}

${ }^{(1)}$ Médias \pm erro-padrão seguidas de letras iguais não diferem entre si pelo teste Newman-Keuls, a $5 \%$ de probabilidade.
120, o comprimento da raiz foi $36 \%$ maior no último. Quanto à comparação entre as enxertias, a exemplo do observado para o pé-franco 120, o comprimento da raiz foi maior nas plantas constituídas pelo sistema radicular do clone 120 (120/120 e 109A/120, Tabela 2). Isso corrobora observações anteriores que relatam que a maior tolerância à seca está associada, pelo menos em parte, à maior profundidade do sistema radicular do clone 120 (Pinheiro et al., 2005).

Com relação às trocas gasosas, de modo geral, não houve diferença em $A, g_{s}$ e na razão $C_{i} / C_{a}$ entre os pés-francos, enxertias e autoenxertias sob irrigação, à exceção da combinação 109A/109A, que apresentou maiores valores de $\mathrm{A}$ e $\mathrm{g}_{\mathrm{s}}$ em relação às demais (Tabela 3). Os valores de $g_{s}, A, E$ e a razão $C_{i} / C_{a}$ sob $\Psi_{a m}$ de -3,0 MPa foram, como esperado, significativamente menores do que os das plantas irrigadas. Contudo, reduções mais pronunciadas $(\sim 75 \%)$ em A foram observadas nos pés-francos do clone 109A e na autoenxertia 109A/109A, quando comparados com os decréscimos $(\sim 55 \%)$ nessa variável, observados entre os pés-francos do clone 120 e na autoenxertia 120/120. Observou-se, ainda, que o comportamento das trocas gasosas do enxerto 109A foi influenciado pelo porta-enxerto 120 , pois, na enxertia $109 \mathrm{~A} / 120$, a redução de A foi em torno de $60 \%$, em contraste com $75 \%$ de redução para o tratamento 109A/109A. Sob deficit hídrico severo, não foram observadas diferenças em $g_{s}$ e em $E$ entre os pés-francos, enxertias e autoenxertias. Por sua vez, a razão $C_{i} / C_{a}$ foi maior nos pés-francos 120 e na autoenxertia $120 / 120$ que nos pés-francos 109A e na autoenxertia 109A/109A. Nas enxertias 120/109A e 109A/120, também foi possível verificar menor razão $\mathrm{C}_{\mathrm{i}} / \mathrm{C}_{\mathrm{a}}$ que no pé-franco 109A e na autoenxertia 109A/109A.

Tabela 2. Características morfológicas de pés-francos dos clones 109A e 120 de Coffea canephora e de suas enxertias recíprocas, em condições irrigadas ${ }^{(1)}$.

\begin{tabular}{|c|c|c|c|c|c|c|}
\hline Variável & $109 \mathrm{~A}$ & 120 & $109 \mathrm{~A} / 109 \mathrm{~A}$ & $120 / 120$ & $109 \mathrm{~A} / 120$ & $120 / 109 \mathrm{~A}$ \\
\hline Comprimento do caule (m) & $0,37 \pm 0,02 \mathrm{a}$ & $0,32 \pm 0,01 b$ & $0,36 \pm 0,02 \mathrm{a}$ & $0,28 \pm 0,01 \mathrm{~b}$ & $0,35 \pm 0,02 \mathrm{a}$ & $0,31 \pm 0,02 \mathrm{a}$ \\
\hline Diâmetro do caule $(\mathrm{cm})$ & $0,54 \pm 0,01 \mathrm{a}$ & $0,52 \pm 0,02 \mathrm{a}$ & $0,51 \pm 0,03 \mathrm{a}$ & $0,47 \pm 0,01 \mathrm{a}$ & $0,51 \pm 0,02 \mathrm{a}$ & $0,31 \pm 0,02 \mathrm{a}$ \\
\hline Área foliar $\left(\mathrm{m}^{2}\right)$ & $0,26 \pm 0,03 a$ & $0,25 \pm 0,02 \mathrm{a}$ & $0,19 \pm 0,04 b$ & $0,16 \pm 0,04 \mathrm{~b}$ & $0,18 \pm 0,03 b$ & $0,19 \pm 0,02 b$ \\
\hline Massa de matéria seca da raiz $(\mathrm{g})$ & $9,65 \pm 0,81 \mathrm{a}$ & $8,04 \pm 0,18 b$ & $6,84 \pm 0,71 b$ & $4,94 \pm 0,03 \mathrm{a}$ & $7,24 \pm 0,56 b$ & $7,04 \pm 0,68 b$ \\
\hline Comprimento da raiz $(\mathrm{m})$ & $0,53 \pm 0,02 \mathrm{c}$ & $0,72 \pm 0,02 \mathrm{a}$ & $0,53 \pm 0,02 \mathrm{c}$ & $0,63 \pm 0,02 b$ & $0,64 \pm 0,01 b$ & $0,57 \pm 0,02 \mathrm{bc}$ \\
\hline Biomassa total $(\mathrm{g})$ & $58,88 \pm 4,50 \mathrm{a}$ & $49,72 \pm 4,92 b$ & $41,81 \pm 4,74 b$ & $32,86 \pm 1,95 \mathrm{c}$ & $40,40 \pm 1,80 \mathrm{~b}$ & $43,33 \pm 2,70 b$ \\
\hline $\mathrm{Mr} / \mathrm{Ma}\left(\mathrm{g} \mathrm{g}^{-1}\right)$ & $0,20 \pm 0,02 \mathrm{a}$ & $0,19 \pm 0,01 \mathrm{a}$ & $0,20 \pm 0,03 \mathrm{a}$ & $0,19 \pm 0,01 \mathrm{a}$ & $0,22 \pm 0,02 \mathrm{a}$ & $0,19 \pm 0,02 \mathrm{a}$ \\
\hline $\mathrm{Mr} / \mathrm{Af}\left(\mathrm{g} \mathrm{m}^{-2}\right)$ & $36,97 \pm 3,50 \mathrm{a}$ & $33,01 \pm 4,03 \mathrm{ab}$ & $35,44 \pm 2,50 \mathrm{a}$ & $30,12 \pm 4,50 b$ & $40,22 \pm 4,30 \mathrm{a}$ & $38,05 \pm 3,25 \mathrm{a}$ \\
\hline
\end{tabular}

${ }^{(1)}$ Médias \pm erro-padrão seguidas de letras iguais não diferem entre si pelo teste de Newman-Keuls, a 5\% de probabilidade. Mr/Ma, razão entre massa de matéria seca da raiz e massa de matéria seca da parte aérea. Mr/Af, razão entre massa de matéria seca da raiz e área foliar. 
Independentemente das combinações entre enxerto e porta-enxerto utilizadas, as reduções em $g_{s}$ pelo deficit hídrico foram mais acentuadas que as reduções em A (Tabela 3). Esses dados são indicativos de que a redução da fotossíntese pelo estresse hídrico foi associada, principalmente, a limitações à difusão do $\mathrm{CO}_{2}$, e não a limitações bioquímicas da maquinaria fotossintética (DaMatta \& Ramalho, 2006). Observou-se, também, que o fechamento estomático provavelmente acarretou decréscimos, proporcionalmente, maiores à transpiração do que à fotossíntese, já que a eficiência instantânea do uso da água $(\mathrm{A} / \mathrm{E})$ aumentou em condições de estresse hídrico.

Sob deficit hídrico, as plantas 120 pé-franco e 109A/120 apresentaram $\mathrm{A} / \mathrm{E}$ superior à das plantas 109A pé-franco, 120/109A, 109A/109A e 120/120 (Tabela 3). Esse resultado revela que o clone 120, utilizado como porta-enxerto, contribuiu para aumentar a A/E das plantas. A ausência de diferença significativa entre a $\mathrm{A} / \mathrm{E}$ da enxertia $120 / 120$ e a das enxertias que tiveram o clone 109A como porta-enxerto indica um certo efeito prejudicial da autoenxertia do clone 120 sobre essa variável. Nas enxertias 120/109A, a A/E também foi maior que no pé-franco 109A, o que sugere que a parte aérea do enxerto 120 possui mecanismos que contribuem para uma maior $\mathrm{A} / \mathrm{E}$.

Sob $\Psi_{\text {am }}$ de -3,0 MPa, o aumento da concentração de glicose, em relação ao regime hídrico irrigado, ocorreu somente nos pés-francos do clone 109A ou nas plantas que possuíam esse clone como enxerto (Tabela 4). Em relação ao teor de frutose, somente o pé-franco
109A e a autoenxertia 109A/109A apresentaram diferenças entre as plantas sob regime hídrico irrigado e sob deficit, mas apenas no $\Psi_{\text {am }}$ de -1,5 MPa.

Concentrações de sacarose e amido foliar sofreram forte redução nas plantas submetidas ao deficit hídrico, independentemente de sua severidade e dos tratamentos (Tabela 4). Os níveis de redução de sacarose foram, em média, de $38 \%$, a $\Psi_{\text {am }}$ de $-1,5 \mathrm{MPa}$, e de $57 \%$, a $\Psi_{\text {am }}$ de -3,0 MPa. De acordo com Praxedes et al. (2006), a redução da concentração de sacarose, sob deficit hídrico severo, ocorre tanto em razão da diminuição da síntese quanto do aumento na degradação, pela inibição da atividade da enzima sintase da sacarose-fosfato e aumento da atividade da invertase ácida, respectivamente. Nas plantas sob deficit hídrico, independentemente da severidade, a percentagem média de redução da concentração de amido foi de $70 \%$. Com efeito, tal redução é uma resposta bem caracterizada em café em condições de deficit hídrico (DaMatta et al., 1997; Praxedes et al., 2006). Ela pode estar relacionada à necessidade de as plantas com déficit hídrico manterem a exportação de sacarose para as raízes, em uma tentativa de adaptação à seca, e de apresentarem queda significativa da fotossíntese (Taiz \& Zeiger, 2004).

A concentração de aminoácidos aumentou significativamente em todas as plantas submetidas ao deficit hídrico (Tabela 4). Esse aumento foi mais pronunciado no pé-franco 109A e na autoenxertia 109A/109A, quando comparado ao pé-franco 120 e à autoenxertia 120/120. O acúmulo de aminoácidos sob deficit hídrico pode ser resultante da redução na síntese

Tabela 3. Condutância estomática $\left(\mathrm{g}_{\mathrm{s}}\right)$, taxa líquida de assimilação do $\mathrm{CO}_{2}(\mathrm{~A})$, taxa transpiratória, razão entre as concentrações interna e externa de $\mathrm{CO}_{2}\left(\mathrm{C}_{\mathrm{i}} / \mathrm{C}_{\mathrm{a}}\right)$ e eficiência do uso da água $(\mathrm{A} / \mathrm{E})$, nos pés-francos dos clones 109A e 120 de Coffea canephora e nas suas enxertias recíprocas ${ }^{(1)}$.

\begin{tabular}{|c|c|c|c|c|c|}
\hline Tratamento & $\mathrm{g}_{\mathrm{s}}\left(\mathrm{mmol} \mathrm{m} \mathrm{m}^{-2} \mathrm{~s}^{-1}\right)$ & $\mathrm{A}\left(\mu \mathrm{mol} \mathrm{m}^{-2} \mathrm{~s}^{-1}\right)$ & $\begin{array}{c}\text { Taxa transpiratória } \\
\left(\mathrm{mmol} \mathrm{m} \mathrm{m}^{-2} \mathrm{~s}^{-1}\right)\end{array}$ & Razão $\mathrm{C}_{\mathrm{i}} / \mathrm{C}_{\mathrm{a}}$ & $\mathrm{A} / \mathrm{E}$ \\
\hline & \multicolumn{5}{|c|}{ Regime hídrico irrigado } \\
\hline $109 \mathrm{~A}$ & $120,7 \pm 28,8 b$ & $7,11 \pm 0,33 b$ & $1,43 \pm 0,25 \mathrm{ab}$ & $0,67 \pm 0,05 \mathrm{a}$ & $5,57 \pm 0,86 \mathrm{ab}$ \\
\hline 120 & $110,0 \pm 32,8 b$ & $7,29 \pm 0,28 b$ & $1,22 \pm 0,29 b$ & $0,62 \pm 0,08 \mathrm{a}$ & $7,36 \pm 1,73 a$ \\
\hline $109 \mathrm{~A} / 109 \mathrm{~A}$ & $252,5 \pm 21,1 \mathrm{a}$ & $9,11 \pm 0,55 \mathrm{a}$ & $1,91 \pm 0,09 \mathrm{a}$ & $0,75 \pm 0,05 \mathrm{a}$ & $4,81 \pm 0,35 b$ \\
\hline $120 / 120$ & $137,5 \pm 11,1 b$ & $7,79 \pm 0,46 b$ & $1,27 \pm 0,063 b$ & $0,67 \pm 0,04 \mathrm{a}$ & $6,12 \pm 0,21 \mathrm{ab}$ \\
\hline $109 \mathrm{~A} / 120$ & $164,2 \pm 14,7 b$ & $7,01 \pm 0,50 b$ & $1,60 \pm 0,054 \mathrm{ab}$ & $0,76 \pm 0,06 \mathrm{a}$ & $4,38 \pm 0,32 b$ \\
\hline \multirow[t]{2}{*}{$120 / 109 \mathrm{~A}$} & $166,7 \pm 10,8 b$ & $7,28 \pm 0,57 b$ & $1,71 \pm 0,08 \mathrm{a}$ & $0,75 \pm 0,01 \mathrm{a}$ & $4,26 \pm 0,27 b$ \\
\hline & \multicolumn{5}{|c|}{ Regime hídrico sob déficit $\left(\Psi_{\mathrm{am}}=-3,0 \mathrm{MPa}\right)$} \\
\hline $109 \mathrm{~A}$ & $9,3 \pm 4,5 \mathrm{~A}^{*}$ & $1,91 \pm 0,25 C^{*}$ & $0,22 \pm 0,04 \mathrm{~A}^{*}$ & $0,44 \pm 0,06 A^{*}$ & $8,71 \pm 1,12 \mathrm{C}^{*}$ \\
\hline 120 & $7,3 \pm 3,4 \mathrm{~A}^{*}$ & $3,13 \pm 0,58 \mathrm{BC}^{*}$ & $0,17 \pm 0,03 \mathrm{~A}^{*}$ & $0,20 \pm 0,02 \mathrm{BC}^{*}$ & $18,15 \pm 1,09 A^{*}$ \\
\hline $109 \mathrm{~A} / 109 \mathrm{~A}$ & $8,7 \pm 2,3 \mathrm{~A}^{*}$ & $2,31 \pm 0,29 \mathrm{BC}^{*}$ & $0,23 \pm 0,02 \mathrm{~A}^{*}$ & $0,39 \pm 0,02 \mathrm{~A}^{*}$ & $10,05 \pm 1,24 \mathrm{BC}^{*}$ \\
\hline $120 / 120$ & $9,7 \pm 2,0 A^{*}$ & $4,59 \pm 0,36 A^{*}$ & $0,34 \pm 0,03 \mathrm{~A}^{*}$ & $0,26 \pm 0,05 \mathrm{AB}^{*}$ & $13,72 \pm 0,86 \mathrm{~B}^{*}$ \\
\hline $109 \mathrm{~A} / 120$ & $5,0 \pm 2,9 \mathrm{~A}^{*}$ & $3,50 \pm 0,43 \mathrm{AB}^{*}$ & $0,19 \pm 0,03 \mathrm{~A}^{*}$ & $0,06 \pm 0,02 \mathrm{C}^{*}$ & $18,74 \pm 1,33 \mathrm{~A}^{*}$ \\
\hline $120 / 109 \mathrm{~A}$ & $8,0 \pm 2,9 \mathrm{~A}^{*}$ & $3,69 \pm 0,22 \mathrm{AB}^{*}$ & $0,32 \pm 0,05 \mathrm{~A}^{*}$ & $0,18 \pm 0,06 \mathrm{BC}^{*}$ & $12,21 \pm 1,48 \mathrm{~B} *$ \\
\hline
\end{tabular}


Tabela 4. Concentrações foliares $\left(\mathrm{mmol} \mathrm{kg}{ }^{-1}\right)$ de glicose, frutose, sacarose, amido, aminoácidos totais e prolina nos pés-francos dos clones 109A e 120 de Coffea canephora, e nas suas enxertias recíprocas, sob condições de déficit hídrico moderado e severo ${ }^{(1)}$.

\begin{tabular}{|c|c|c|c|c|c|c|c|c|c|c|c|c|}
\hline \multirow[t]{2}{*}{ Tratamento } & \multicolumn{2}{|r|}{ Glicose } & \multicolumn{2}{|r|}{ Frutose } & \multicolumn{2}{|c|}{ Sacarose } & \multicolumn{2}{|c|}{ Amido } & \multicolumn{2}{|c|}{ Aminoácidos totais } & \multicolumn{2}{|c|}{ Prolina } \\
\hline & Irrigado & Sob deficit & Irrigado & Sob deficit & Irrigado & Sob deficit & Irrigado & Sob deficit & Irrigado & Sob deficit & Irrigado & Sob deficit \\
\hline & \multicolumn{12}{|c|}{ Deficit hídrico moderado $\left(\Psi_{\mathrm{am}}=-1,5 \mathrm{MPa}\right)$} \\
\hline 09A & $7 \mathrm{abA}$ & $55 \mathrm{aA}$ & $8,06 \mathrm{aA}$ & 10,73 &, $16 \mathrm{aB}$ & $33,33 \mathrm{aA}$ & $65,57 \mathrm{aB}$ & $29,10 \mathrm{aA}$ & $365,70 \mathrm{bA}$ & bB & $58 \mathrm{aA}$ & $71 \mathrm{bB}$ \\
\hline 0 & $4 \mathrm{aA}$ & & & & $3 \mathrm{aB}$ & & & & & & & $3 \mathrm{aA}$ \\
\hline 99A & $95 \mathrm{abA}$ & $9,29 \mathrm{abA}$ & $9,12 \mathrm{aA}$ & 12, & & & $\mathrm{aB}$ & & bA & & aA & $7 \mathrm{bB}$ \\
\hline $120 /$ & $66 \mathrm{aA}$ & $7,14 \mathrm{aA}$ & 7,04aA & $6,34 \mathrm{aA}$ & $\mathrm{aB}$ & & & & & & BaA & $4 \mathrm{aA}$ \\
\hline & & & & & & & & & & & & $\mathrm{abB}$ \\
\hline \multirow[t]{2}{*}{$120 / 109 \mathrm{~A}$} & & & abA & & 3,69aB & $37,40 \mathrm{aA}$ & $57,70 \mathrm{aB}$ & $27,58 \mathrm{aA}$ & A & & $\mathrm{aA}$ & $0 \mathrm{aA}$ \\
\hline & \multicolumn{12}{|c|}{ Deficit hídrico severo $\left(\Psi_{\mathrm{am}}=-3,0 \mathrm{MPa}\right)$} \\
\hline 09A & A & & & &, $07 \mathrm{aB}$ & & & taA & bA & & aA & $1 \mathrm{cB}$ \\
\hline & & & & & & & & & & & & \\
\hline $109 \mathrm{~A}$ & $A$ & & $\mathrm{pA}$ & & & & & & & & $\mathrm{aA}$ & $\mathrm{cB}$ \\
\hline $120 / 120$ & $36 \mathrm{aA}$ & $6,29 \mathrm{aA}$ & 7,08aA & 6 , &, $59 \mathrm{aB}$ & $50,09 \mathrm{aA}$ & $54,99 \mathrm{aB}$ & $24,27 \mathrm{aA}$ & $260,59 \mathrm{aA}$ & 316 & $3,69 \mathrm{aA}$ & $5,10 \mathrm{abB}$ \\
\hline $109 \mathrm{~A} / 12$ & $8,19 \mathrm{bA}$ & $11,16 \mathrm{bB}$ & $10,88 \mathrm{bA}$ & $10,30 \mathrm{bA}$ & $63,28 \mathrm{aB}$ & $27,79 \mathrm{aA}$ & $60,18 \mathrm{aB}$ & $24,58 \mathrm{aA}$ & $296,37 \mathrm{abA}$ & $354,65 \mathrm{abB}$ & $2,62 \mathrm{aA}$ & $5,54 \mathrm{abB}$ \\
\hline 120/109A & $19 \mathrm{bA}$ & $8,08 \mathrm{abA}$ & $9,23 \mathrm{abA}$ & $9,69 \mathrm{aA}$ & $59,52 \mathrm{aB}$ & $23,10 \mathrm{aA}$ & $57,32 \mathrm{aB}$ & $28,74 \mathrm{aA}$ & $238,55 \mathrm{aA}$ & $351,33 \mathrm{aB}$ & $4,07 \mathrm{aA}$ & $3,60 \mathrm{aA}$ \\
\hline
\end{tabular}

${ }^{(1)}$ Médias seguidas de letras iguais, minúsculas nas colunas e maiúsculas nas linhas (em uma mesma variável), não diferem entre si pelo teste de Newman-Keuls, a $5 \%$ de probabilidade.

de proteínas e da associação de mRNA com polissomas (Kawaguchi et al., 2004), ou do aumento da degradação de proteínas (Catala et al., 2007). Em todo o caso, o acúmulo de aminoácidos, particularmente prolina, pode contribuir para o ajuste osmótico, de forma a minimizar os impactos prejudiciais da seca sobre as plantas (Taiz \& Zeiger, 2004).

Independentemente da severidade do deficit hídrico, o pé-franco 109A e a autoenxertia 109A/109A apresentaram maiores concentrações de prolina na folha do que o pé-franco 120 e a autoenxertia 120/120. Sob condições de deficit severo, o clone 109A, quando enxertado sobre o clone 120, apresentou menores concentrações de prolina que os tratamentos 109A e a autoenxertia 109A/109A e semelhantes aos tratamentos pé-franco 120, autoenxertia 120/120 e enxertia 120/109A.

Vários trabalhos indicam que a prolina pode ser um indicador da severidade do estresse, ao invés de estar associada a um mecanismo protetor (Verbruggen \& Hermans, 2008), o que parece ser o caso no presente trabalho. Assim, o acúmulo desse aminoácido só seria promovido caso a desidratação celular ultrapassasse um limiar de dano à célula, sendo sua acumulação mais notória em genótipos mais sensíveis. Entretanto, isso não excluiria a possibilidade de que, em outros genótipos, o aumento no teor de prolina possa contribuir para tolerância à seca.

Muitos trabalhos postulam que o aumento na concentração de solutos orgânicos em tecidos de plantas expostas ao deficit hídrico produz um ajustamento osmótico e reduz a desidratação celular, com preservação de estruturas celulares (Valliyodan \& Nguyen, 2006; Ferreira-Silva et al., 2009). De acordo com Ashraf \& Ahmad (2000) e Valliyodan \& Nguyen (2006), o acúmulo de solutos compatíveis, como prolina, glicina-betaína e polióis, entre outros compostos, tem importante papel de osmoproteção. Todavia, o acúmulo de hexoses, aminoácidos e prolina observado neste trabalho sob condições de deficit hídrico, mais pronunciadamente nas plantas sensíveis à seca, evidencia que o acúmulo desses solutos não esteve associado à maior tolerância à seca, e foi consequência do deficit hídrico. Dessa forma, o ajustamento osmótico resultante seria mais uma resposta adaptativa a limites superiores de desidratação associados à seca do que propriamente um mecanismo efetivo de tolerância ao deficit hídrico, o que está de acordo com Serraj \& Sinclair (2002).

\section{Conclusões}

1. Enxertias de materiais sensíveis à seca em porta-enxertos tolerantes aumentam a tolerância à seca e a eficiência do uso da água pelas plantas.

2. Sob deficit hídrico severo, os teores de amido e de sacarose diminuem e os de aminoácidos totais aumentam.

3. Sob deficit hídrico severo, os teores de glicose e de prolina aumentam, particularmente nos tratamentos com o clone sensível ao deficit hídrico usado como enxerto ou pé-franco. 
4. O ajuste osmótico potencial no clone sensível ao deficit hídrico usado como enxerto não é um mecanismo efetivo de tolerância à seca, mas provavelmente um componente de um mecanismo de adaptação ao estresse hídrico.

\section{Agradecimentos}

Ao Conselho Nacional de Desenvolvimento Científico e Tecnológico, à Coordenação de Aperfeiçoamento de Pessoal de Nível Superior, à Fundação de Amparo à Pesquisa do Estado de Minas Gerais e ao Ministério da Ciência e Tecnologia.

\section{Referências}

ASHRAF, M.; AHMAD, S. Influence of sodium chloride on ion accumulation, yield components and fibre characteristics in salt tolerant and salt-sensitive lines of cotton (Gossypium hirsutum L.). Field Crops Research, v.66, p.115-127, 2000.

ATKINSON, C.J.; ELSE, M.A.; TAYLOR, L.; DOVER, C.J. Root and stem hydraulic conductivity as determinants of growth potential in grafted trees of apple (Malus pumila Mill.). Journal of Experimental Botany, v.54, p.1221-1229, 2003.

ATKINSON, C.J.; POLICARPO, M.; WEBSTER, A.D.; KINGSWELL, G. Drought tolerance of clonal Malus determined from measurements of stomatal conductance and leaf water potential. Tree Physiology, v.20, p.557-563, 2000.

BARROS, R.S.; MAESTRI, M.; VIEIRA, M.;BRAGA-FILHO,L.J. Determinação de área de folhas do café (Coffea arabica L. cv. 'Bourbon Amarelo'). Revista Ceres, v.20, p.44-52, 1973.

CATALA, R.; OUYANG, J.; ABREU, I.A.; HU, Y.; SEO, H.; ZHANG, X.; CHUA, N.H. The Arabidopsis E3 SUMO ligase SIZ1 regulates plant growth and drought responses. Plant Cell, v.19, p.2952-2966, 2007.

DAMATTA, F.M.; CHAVES, A.R.M.; PINHEIRO, H.A.; DUCATTI, C.; LOUREIRO, M.E. Drought tolerance of two field-grown clones of Coffea canephora. Plant Science, v.164, p.111-117, 2003.

DAMATTA, F.M.; LOOS, R.A.; SILVA, E.A.; LOUREIRO, M.E. Limitations to photosynthesis in Coffea canephora as a result of nitrogen and water availability. Journal of Plant Physiology, v.159, p.975-981, 2002.

DAMATTA, F.M.; MAESTRI, M.; BARROS, R.S. Photosynthetic performance of two coffee species under drought. Photosynthetica, v.34, p.257-264, 1997.

DAMATTA, F.M.; RAMALHO, J.D.C. Impacts of drought and temperature stress on coffee physiology and production: a review. Brazilian Journal of Plant Physiology, v.18, p.55-81, 2006.

FAHL, J.I.; CARELLI, M.L.C.; MENEZES, H.C.; GALLO, P.B.; TRIVELIN, P.C.O. Gas exchange, growth, yield and beverage quality of Coffea arabica cultivars grafted on to C. canephora and C. congensis. Experimental Agriculture, v.37, p.241-252, 2001.
FERREIRA, D.F. SISVAR: um programa para análises e ensino de estatística. Revista Symposium, v.6, p.36-41, 2008.

FERREIRA-SILVA, S.L.; VOIGT, E.L.; VIÉGAS, R.A.; PAIVA, J.R. de; SILVEIRA, J.A.G. Influência de porta-enxertos na resistência de mudas de cajueiro ao estresse salino. Pesquisa Agropecuária Brasileira, v.44, p.361-367, 2009.

GUIMARÃES, P.T.G.; GARCIA, A.W.R.; ALVAREZ V., V.H.; PREZOTTI, L.C.; VIANA, A.S.; MIGUEL, A.E.; MALAVOLTA, E.; CORRÊA, J.B.; LOPES, A.S.; NOGUEIRA, F.D.; MONTEIRO, A.V.C. Cafeeiro. In: RIBEIRO, A.C.; GUIMARÃES, P.T.G.; ALVAREZ V., V.H. (Ed.). Recomendação para o uso de corretivos e fertilizantes em Minas Gerais: 5_- aproximação. Viçosa: Comissão de Fertilidade do Solo do Estado de Minas Gerais, 1999. p.289-302.

HARTMANN, H.T.; KESTER, D.E.; DAVIES, F.T.; GENEVE, R.L. Plant propagation: principles and practices. $7^{\text {th }}$ ed. Upper Sanddle River: Prentice Hall, 2002. 849p.

KAWAGUCHI, R.; GIRKE, T.; BRAY, E.A.; BAILEY-SERRES, J. Differential mRNA translation contributes to gene regulation under non-stress and dehydration stress conditions in Arabidopsis thaliana. Plant Journal, v.38, p.823-839, 2004.

LACONO, F.; BUCCELA, A.; PETERLUNGER, E. Water stress and rootstock influence on leaf gas exchange of grafted and ungraf grapevines. Scientia Horticulture, v.75, p.27-39, 1998.

PINHEIRO, H.A.; DAMATTA, F.M.; CHAVES, A.R.M.; LOUREIRO, M.E.; DUCATTI, C. Drought tolerance is associated with rooting depth and stomatal control of water use in clones of Coffea canephora. Annals of Botany, v.96, p.101-108, 2005.

POLICARPO, C.J.; WEBSTER, A.D.; KINGSWELL, G. Drought tolerance of clonal Malus determined from measurements of stomatal conductance and leaf water potential. Tree Physiology, v.20, p.557-563, 2000.

PRAXEDES, S.C.; DAMATTA, F.M.; LOUREIRO, M.E.; FERRÃO, M.A.G.; CORDEIRO, A.T. Effects of long-term soil drought on photosynthesis and carbohydrate metabolism in mature robusta coffee (Coffea canephora Pierre var. kouillou) leaves. Environmental and Experimental Botany, v.56, p.263-273, 2006.

RONCHI, C.P.; DAMATTA, F.M. Aspectos fisiológicos do café conilon. In: FERRÃO, R.G.; FONSECA, A.F.A. da; BRAGANÇA, S.M.; FERRÃO, M.A.G.; DEMUNER, L.H. (Ed.). Café Conilon. Vitória: Incaper, 2007. p.95-115.

SCHOLANDER, P.F.; HAMMEL, H.T.; BRADSTREET, E.D.; HEMMINGEN, A.E. Sap pressure in vascular plants. Science, v.148, p.339-346, 1965.

SERRAJ, E.; SINCLAIR, T.R. Osmolyte accumulation: can it really help increase crop yield under drought conditions? Plant, Cell and Environment, v.25, p.333-341, 2002.

SORCE, C.; MASSAI, R.; PICCIARELLI, P.; LORENZI. R. Hormonal relationships in xylem sap of grafted and ungrafted Prunus rootstocks. Scientia Horticulturae, v.93, p.333-342, 2002.

TAIZ, L.; ZEIGER, E. Fisiologia vegetal. 3.ed. Porto Alegre: Artmed, 2004. 719p. 
TOMAZ, M.A.; SAKIYAMA, N.S.; DAMATTA, F.M.; MARTINEZ, H.E.P.; CRUZ, C.D.; PEREIRA, A.A. Efeito do porta-enxerto nas trocas gasosas, área foliar e superfície de raiz de mudas de Coffea arabica L. Revista Ceres, v.53, p.237-242, 2006.
VALLIYODAN, B.; NGUYEN, H.T. Understanding regulatory networks and engineering for enhanced drought tolerance in plants. Current Opinion in Plant Biology, v.9, p.189-195, 2006.

VERBRUGGEN, N.; HERMANS, C. Proline accumulation in plants: a review. Amino Acids, v.35, p.753-759, 2008.

$\overline{\text { Recebido em } 6 \text { de abril de } 2009 \text { e aprovado em } 20 \text { de maio de } 2010}$ 